University of Nebraska - Lincoln

DigitalCommons@University of Nebraska - Lincoln

$9-1-1992$

\title{
Magnetization Of Sm-Fe-N Thin Films With In-Plane Anisotropy
}

D. Wang

University of Nebraska - Lincoln

George C. Hadjipanayis

University of Delaware, hadji@udel.edu

David J. Sellmyer

University of Nebraska-Lincoln, dsellmyer@unl.edu

Follow this and additional works at: https://digitalcommons.unl.edu/physicssellmyer

Part of the Physics Commons

Wang, D.; Hadjipanayis, George C.; and Sellmyer, David J., "Magnetization Of Sm-Fe-N Thin Films With InPlane Anisotropy" (1992). David Sellmyer Publications. 109.

https://digitalcommons.unl.edu/physicssellmyer/109

This Article is brought to you for free and open access by the Research Papers in Physics and Astronomy at DigitalCommons@University of Nebraska - Lincoln. It has been accepted for inclusion in David Sellmyer Publications by an authorized administrator of DigitalCommons@University of Nebraska - Lincoln. 


\title{
Magnetization Of Sm-Fe-N Thin Films With In-Plane Anisotropy
}

\author{
D. Wang ${ }^{(1)}$, G.C. Hadjipanayis ${ }^{(2)}$ and D. J. Sellmyer ${ }^{(1)}$ \\ (1) Behlen Laboratory of Physics and Center for Materials Research and Analysis, University \\ of Nebraska, Lincoln, NE 68588-0111 \\ (2) Department of Physics and Astronomy, University of Delaware, Newark, DE 19716
}

\begin{abstract}
Sm-Fe-N films have been made by dc magnetron sputtering and heating in-situ in nitrogen atmosphere. It is observed that the anisotropy changes from perpendicular to in-plane by nitrogenation. The Curie temperature is about $380 \mathrm{~K}$. Aspects of structure, hysterisis loops, initial magnetization curves and temperature dependence of coercivity are discussed.
\end{abstract}

\section{INTRODUCTION}

Studies show that magnetic properties of bulk rare earth-Fe compounds such as $\mathrm{Sm}_{2} \mathrm{Fe}_{17}$ and $\mathrm{NdFe}_{11} \mathrm{Ti}$ can be greatly improved by gas-phase interstitial modification for the application as a permanent magnet [1]. For example, the $\mathrm{Sm}_{2} \mathrm{Fe}_{17} \mathrm{~N}_{\mathrm{x}}$ compound has some advantageous properties in comparison with the commercial $\mathrm{Nd}_{2} \mathrm{Fe}_{14} \mathrm{~B}$ permanent magnet. A higher Curie temperature $T_{c}$ of $750 \mathrm{~K}$, a higher uniaxial anisotropic field of $140 \mathrm{kOe}$ at room temperature as compared with $590 \mathrm{~K}, 80 \mathrm{kOe}$ for $\mathrm{Nd}_{2} \mathrm{Fe}_{14} \mathrm{~B}$ [2], and a similar saturation magnetization of $4 \pi \mathrm{M}_{\mathrm{s}}=15.4 \mathrm{kG}$ have been reported, as the three most important intrinsic properties for permanent-magnet materials.

It has been demonstrated that permanent magnetic thin films can be grown with new phases and proper microstructure in a very controllable way [3]. This follows because of the many adjustable deposition parameters. Thin films may also lead to certain device applications. We have shown that Sm-Fe films can be made by sputtering [4]. The Curie temperature for the $\mathrm{Sm}$-Fe film was $380 \mathrm{~K}$, which agrees with the value of bulk $\mathrm{Sm}_{2} \mathrm{Fe}_{17}$ with $\mathrm{Th}_{2} \mathrm{Zn}_{17}$ structure. Here we present additional data on the various magnetic properties.

\section{Film Preparation And Measurements}

Sm-Fe films were prepared in a dc magnetron sputtering system. Ta substrate was used at a temperature of $T_{s}=450$ ${ }^{\circ} \mathrm{C}$. Then nitrogen gas was introduced into the chamber with a pressure about 50 Torr at a sample temperature of $450{ }^{\circ} \mathrm{C}$ for about one hour. The base pressure was below $2 \times 10^{-7}$ Torr. The argon gas pressure during sputtering was $40 \mathrm{mTorr}$. The crystal structure was investigated by $\mathrm{x}$-ray diffractometry (XRD) on a Rigaku DMAXB system with $\mathrm{Cu} \mathrm{K}_{\alpha}$ radiation. The microstructure was studied by using a SEM (JeolJSM840A) and a TEM (Jeol-2010). A Quantum Design

Manuscript received February 17, 1992. Work supported by the U.S. DOE under grants DE-FG02-86ER45262 and DE-FG02-86ER45263.
SQUID magnetometer was used to measure the magnetic properties from $5 \mathrm{~K}$ to $400 \mathrm{~K}$, with a maximum field of $55 \mathrm{kOe}$. An alternating gradient force magnetometer (AGFM) was used to measure the initial and remanence magnetization and minor loops at room temperature with a maximum field of $14 \mathrm{kOe}$. Elemental compositions of Sm and Fe were measured by using a Kevex $770 \mathrm{x}$-ray florescence (XRF) analyzer and EDX from the SEM.

\section{Results AND Discussion}

\section{Structural Analysis}

For specified lattice parameters, rare earth-Fe compounds of the form $\mathrm{Th}_{2} \mathrm{Zn}_{17}, \mathrm{TbCu}_{7}$ and $\mathrm{ThMn}_{12}$ are transformation related $[3,5]$. It is difficult to distinguish these structures only from $x$-ray diffraction data for thin films in which only a limited number of lines are available. The observed XRD patterns for $\mathrm{Sm}-\mathrm{Fe}$ and $\mathrm{Sm}-\mathrm{Fe}-\mathrm{N}$ are similar except the peak positions for the latter are moved to lower angle for the latter [4]. An attempt was made to fit the observed peaks to several phases. The major peaks can be fitted to (024), (214), (116) for the $\mathrm{Th}_{2} \mathrm{Zn}_{17}$ structure, (110), (200), (201) for $\mathrm{TbCu}_{7}$ structure, and (002), (202), (222) for the $\mathrm{ThMn}_{12}$ structure. There is an $\alpha$-Fe (110) peak for all the films. For films with different thicknesses the XRD intensity ratio of $\alpha$-Fe to Sm-Fe increases substantially when the thickness decreases. When the film is thinner than $900 \AA$ there is essentially only $\alpha$-Fe peaks left although the composition analysis gives similar results for all the films.

EDX and XRF analysis show similar $\mathrm{Sm} / \mathrm{Fe}$ atomic ratio of about $10 / 90$. The $x$ was estimated to be about 2.7 in the formula of $\mathrm{Sm}_{2} \mathrm{Fe}_{17} \mathrm{~N}_{\mathrm{x}}$ by using the volume expansion, which is about $7 \%$ [4].

\section{Hysteresis Loops}

Fig. 1 gives the loops with applied field in and perpendicular to the film plane for a Sm-Fe film and a Sm-Fe-N film. The two films have similar texture as indicated by the $x$-ray diffraction pattern [4]. The transition of effective anisotropy on nitrogenation [6] from perpendicular to in-plane is observed.

In the second quadrant of the in-plane loops there is a small sharp drop when the field is fairly low, suggesting either the presence of a soft magnetic phase, or a canted anisotropy system, or both. First of all, the $\alpha$-Fe may be the soft phase. To see how much this $\alpha$-Fe phase contributes and how it is 


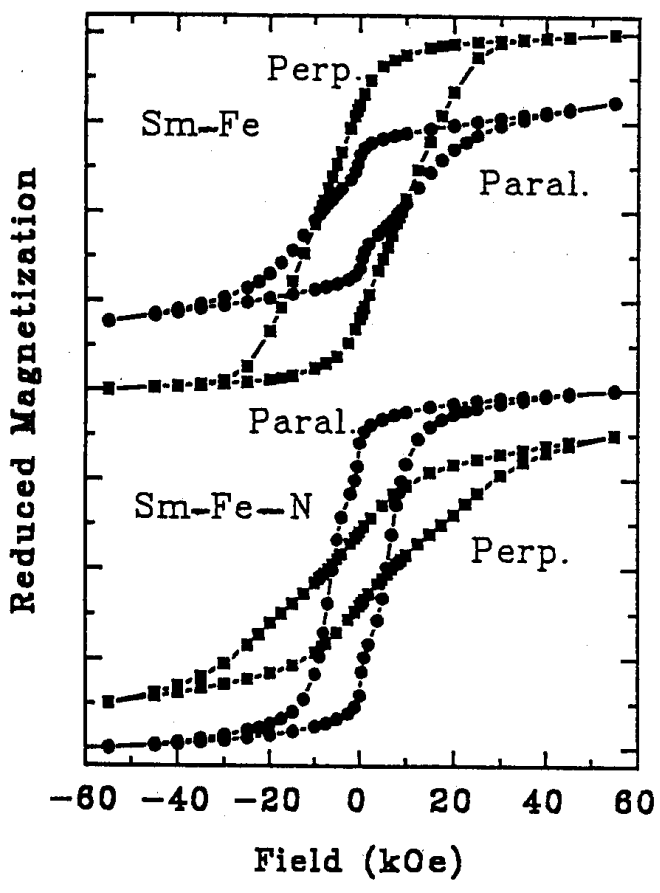

Fig. 1. Hysteresis loops for $\mathrm{Sm}-\mathrm{Fe}$ and $\mathrm{Sm}-\mathrm{Fe}-\mathrm{N}$ films measured at low temperature of $5 \mathrm{~K}$ by SQUID.

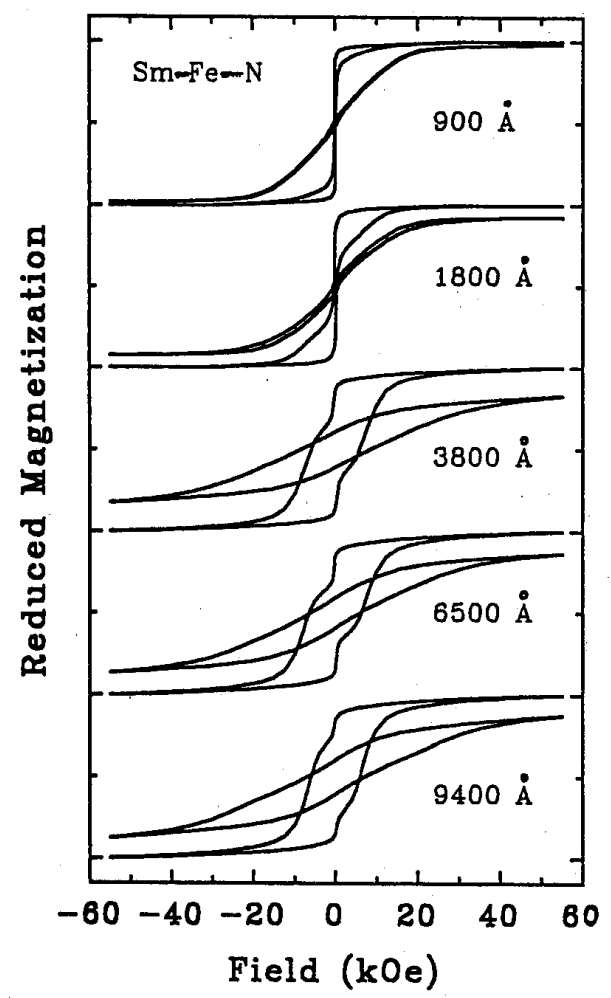

Fig. 2. Hysteresis loops for $\mathrm{Sm}-\mathrm{Fe}-\mathrm{N}$ films with different thicknesses measured at low temperature of $5 \mathrm{~K}$ by SQUID. distributed a series of films with different thicknesses were made under the same preparation conditions. The in-plane loops are shown in Fig. 2. As the film thickness decreases, the fraction of the soft phase increases substantially. When the film is about $900 \dot{A}$ or thinner, basically only the soft phase exists, suggesting a nearly pure soft initial layer close to the substrate. Considering the XRD data a numerical fit was attempted to separate this initial soft layer from all the loops. The result suggests that the initial soft layer contributes the largest part to the sharp drop in the loop. The rest from the bulk part of the film contributes about $5 \%$ of total magnetization. This suggests either there are still soft regions in the bulk part of the film or the bulk phase has a slightly canted anisotropy [7].

Fig. 3 gives the loops of a double-layer film with an $\mathrm{Fe}$ layer purposefully grown underneath the $\mathrm{Sm}-\mathrm{Fe}-\mathrm{N}$ layer. The general features are similar to those discussed above. This suggests that the soft $\alpha-\mathrm{Fe}$ phase might be a major contribution to the magnetization drop mentioned earlier.

\section{Initial curves}

Fig. 4 gives three initial magnetization curves for a typical $\mathrm{Sm}-\mathrm{Fe}-\mathrm{N}$ film in a thermally demagnetized state and field demagnetized state and the maximum magnetization on minor loops, this last is sometimes called the commutation curve. All three curves are almost identical. The magnetization does not increase substantially until the applied field is fairly close to the coercivity of about $3.5 \mathrm{kOe}$. The onset of the magnetization at very small field might due to the soft phase. The small negative overshoot for thermally demagnetized curve is due to the non-ideal thermal demagnetization state for the as-deposited film. Except for the small magnetization rise in low field region, the lack of steep increase of the magnetization at low field for the thermally demagnetized film

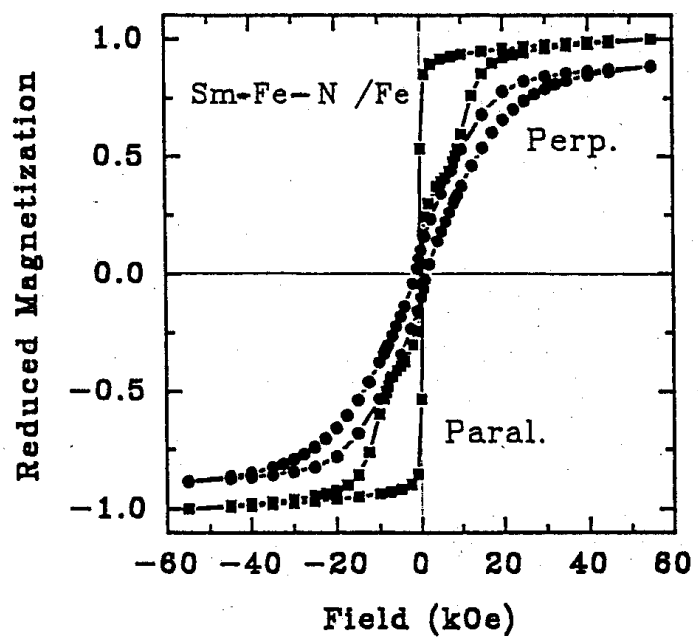

Fig. 3. Hysteresis loops for $\mathrm{Sm}-\mathrm{Fe}-\mathrm{N} / \mathrm{Fe}$ of $5000 \AA / 5000 \mathrm{~A}$ bilayer film measured at low temperature of $5 \mathrm{~K}$ by SQUID. 


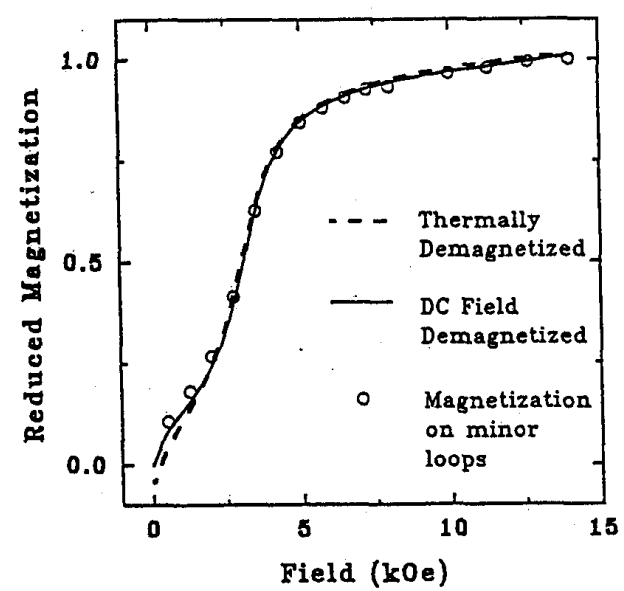

Fig. 4. Initial magnetization curves for a Sm-Fe-N film in a thermally demagnetized state and field demagnetized state, and magnetization from minor loops by AGFM.

may result because there are not enough easily movable domain walls inside each grain. This is a contrary to the case of the sintered $\mathrm{Nd}_{2} \mathrm{Fe}_{14} \mathrm{~B}$ magnet where nucleation is believed the dominant coercivity mechanism [8]. The curve is also different from the case for typical pinning behavior [9].

\section{Temperature dependence of coercivity}

Because of the high anisotropy field and limited applied field available only coercivities from the perpendicular loop for $\mathrm{Sm}$ $\mathrm{Fe}$ and in-plane loop for the Sm-Fe-N sample, which are with

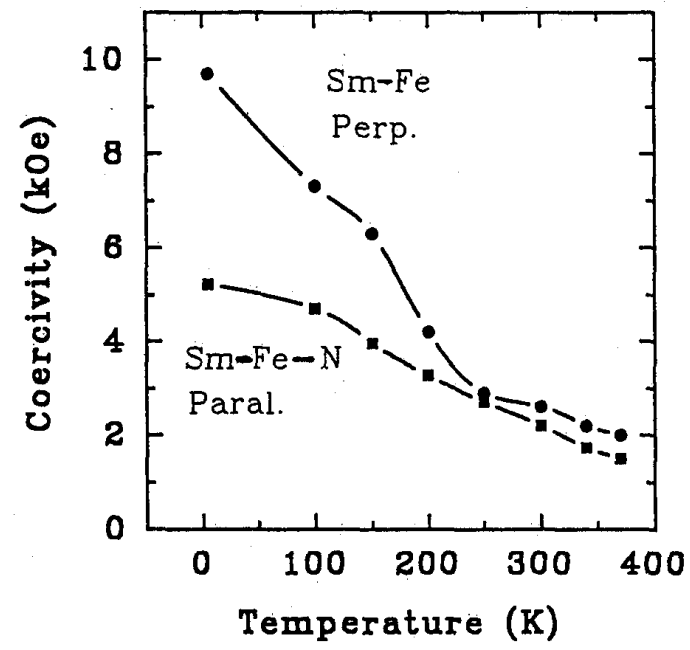

Fig. 5. Temperature dependence of the perpendicular coercivity for a $\mathrm{Sm}-\mathrm{Fe}$ film and in-plane coercivity for a Sm-Fe-N film. easy directions, are plotted in Fig. 5. It should be noted that there is some structure in the curve for the Sm-Fe-N sample around 100 to $200 \mathrm{~K}$. This might indicate that there is some change in the anisotropy direction, which could include a canting or cone-shaped anisotropy.

Mukai and Fujimoto [10] observed experimentally that the domain size is about $1 \mu \mathrm{m}$ on a multi-domain bulk $\mathrm{Sm}_{2} \mathrm{Fe}_{17} \mathrm{~N}_{x}$ sample by using a Kerr microscope. Sagawa and coworkers [11] observed that the critical single-domain size for $\mathrm{Nd}_{2} \mathrm{Fe}_{14} \mathrm{~B}$, $\mathrm{Sm}_{2} \mathrm{Co}_{17}$, and $\mathrm{SmCo}_{5}$ are $0.26,0.66$ and $1.6 \mu \mathrm{m}$ respectively. The three most relevant factors that govern this size, i.e $\mathrm{K}$, $\mathrm{M}_{\mathrm{s}}$, and exchange strength for Sm-Fe-N are in the same range as these three permanent magnets. It is then estimated that the critical size of single-domain grain for $\mathrm{Sm}_{2} \mathrm{Fe}_{17} \mathrm{~N}_{\mathrm{x}}$ is roughly in the same range, though the single-domain grain size should be smaller than the domain size in multi-domain sample under zero applied field. In our case SEM and TEM micrographs show that the grain size is about $3000 \dot{A}$ for Sm-Fe-N films and $1200 \dot{A}$ for Sm-Fe films. So it is likely that the films consist of interacting single-domain grains. The different grain size may also have an effect on the coercivities.

\section{SUMMARY}

$\mathrm{Sm}-\mathrm{Fe}$ and $\mathrm{Sm}-\mathrm{Fe}-\mathrm{N}$ films were synthesized by $\mathrm{dc}$ magnetron sputtering followed by nitrogenation in a low pressure nitrogen atmosphere. A transition of the anisotropy from perpendicular to in-plane was observed. Various magnetization behaviors have been discussed.

\section{ACKNOWLEDGMENTS}

We thank Professor R. Kirby, Professor S.S. Jaswal, Professor Liou, Dr. Z.S. Shan, and Mr. J.X. Shen for various assistance. We thank Professor F. Cadieu for the helpful discussions.

\section{REFERENCES}

[1]. J.M.D. Coey and H. Sun, J.Magn. Magn. Mater. 87, L.251 (1990). and J.M.D. Coey, Phys. Scripta. T39, 21 (1991).

[2]. K.J.Strnat, Proceedings of the IEEE, 78, 923 (1990).

[3]. D.J. Sellmyer, J. Alloys Comp.(in press). and F.T. Cadieu, H. Hegde, R. Rani, A. Navarathna and K. Chen, Appl. Phys. Lett., 59, 875 (1991).

[4]. D. Wang, S.H. Liou, P. He, D.J. Sellmyer and G.C. Hadjipanayis, (To be published).

[5]. H. Saito, M. Takahashi, and T. Wakiyama, J. Appl. Phys. 64, 5965 (1988).

[6]. M.W. Dirken, R.C. Thiel, L.J. De Jongh, T.H. Jacobs and K.H.J. Buschow, J. Less-Comm. Metals, 155, 339 (1989).

[7] F.J. Cadieu, Private communications.

[8] S. Miraglia, J.L. Soubeyroux, C. Kolbeck, O. Isnard, D. Fruchart and M. Guillot, J. Less-Comm Metals, 171, 51 (1991).

[9] T. Suzuki, H. Notarys, D. Dobertin, C.J. Lin, D. Weller, D. Miller, and G. Gorman, Intermag-92. Paper \#FB-06.

[10]. T. Mukai and T. Fujimoto, J.Magn. Magn. Mater. 103, 165 (1992).

[11]. M. Sagawa, S. Hirosawa, H. Yamamoto, S. Fujimura and Y. Matsuura, Jpn. J. Appl. Phys. 26, 785 (1987). 